\title{
As Origens da Educação no Brasil Da hegemonia católica às primeiras tentativas de organização do ensino
}

\author{
Marcos Marques de Oliveira
}

"No Brasil imperial, como na Turquia de Ataturk, a educação era a marca distintiva da elite política. Havia um verdadeiro abismo entre essa elite e o grosso da população em termos educacionais".

(José Murilo de Carvalho)

\section{Resumo}

Este artigo analisa os efeitos do processo europeu de modernização no Brasil, em especial no que se refere ao atraso da implantação de uma estrutura de ensino organizada com base em um sistema nacional. De acordo com a nossa hipótese, da mesma forma como faltou no Brasil um movimento social que buscasse a criação de um ethos científico, do qual o sistema universitário europeu seria o grande modelo, segundo a interpretação de Simon Schwartzman, o mesmo ocorreu para a constituição de um sistema de educação pública, de caráter laico e universal.

Palavras-chaves: Educação. História. Igreja Católica. Ensino Superior. Educação Básica. República.

\section{Introdução}

A sociedade capitalista é resultante de três revoluções: a Revolução Industrial, ocorrida, em meados do século XVIII, na Inglaterra; a Democrática, que se passou na França, em 1789; e a Educacional, que enraizada no lluminismo, somente se completa na Europa do século XX. Mesmo considerando o fato de não terem sido historicamente simultâneas nem geograficamente extensas, estas revoluções correspondem, segundo o sociólogo Talcott Parsons (1971), aos três processos estruturais responsáveis pela consolidação das sociedades ocidentais do noroeste da Europa, a partir do século XVII.

Na hipótese deste autor, estas revoluções são processos de diferenciação funcional dos subsistemas econômico, político e cultural, que conferem crescente complexidade às sociedades modernas. Das suas interações é que se configuraram as sociedades de economia altamente desenvolvidas, socialmente inclusivas e politicamente liberais — todas com grande capacidade de expansão das forças produtivas, autonomia na auto-re- 
gulação dos conflitos e uma organização política baseada no consenso e na legitimidade dos valores da representação.

Neste artigo, analisaremos os efeitos deste fenômeno no Brasil, em especial no que se refere ao atraso da implantação de uma estrutura de ensino organizada com base em um sistema nacional. De acordo com a hipótese aqui defendida, da mesma forma como faltou, em Portugal e no Brasil, um movimento social mais profundo que buscasse a criação de um ethos científico, do qual o sistema universitário europeu seria o grande modelo, segundo a interpretação de Schwartzman (1979, p. 52), o mesmo ocorreu para constituição de um sistema de educação pública no Brasil, de caráter laico e universal.

\section{A hegemonia católica na Colônia e no Império}

No Brasil Colonial, vis a vis à modernidade européia, estabeleceu-se a herança cultural ibérica através da Igreja Católica com a chegada da Ordem dos Jesuítas em 1549, que sob a inspiração da Contra-Reforma, foi responsável pela catequização indígena e pela educação da elite colonizadora. Como sustenta Xavier (1980), preocupados com a difusão da fé e com a educação de uma elite religiosa, os jesuítas criaram um sistema educacional que, em última instância, fornecia aos elementos das classes dominantes uma educação clássica e humanista como era o ideal europeu da época. No século XVIII, por exemplo, a obra educativa dos jesuítas se estendia do Pará a São Paulo, com 17 colégios e seminários, 25 residências e 36 missões, sem contar os seminários menores e as escolas de alfabetização presentes em quase todo o território (ALBUQUERQUE, 1993).
Sem a concorrência do protestantismo e com as injunções políticas e econômicas da condição colonial, a educação jesuítica reproduziu no Brasil o espírito da ldade Média, com o aprisionamento do homem ao dogma da tradição escolástica, a sua submissão à autoridade e à rígida ordenação social, avesso ao livre exame e à experimentação. Em contraste, portanto, ao homem de livre-pensamento, de visão igualitária e espírito associativo, confiante no conhecimento como instrumento de transformação do mundo natural.

Por outro lado, afirma Albuquerque (1993, p. 18), o projeto educacional jesuítico obteve resultados significativos, tais como: "a transmissão de uma educação homogênea - mesma língua, mesma religião, mesma visão de mundo, mesmo ideal de 'homem culto', ou seja, letrado e erudito - plasmando, de norte a sul, uma identidade cultural; a catequese como processo de aculturação, embora destrutiva, de filhos de colonos e órfãos, trazidos de Portugal, com meninos índios e mestiços, elidindo a distinção de raças e dissolvendo costumes não europeus; a contraposição da escola e da lgreja à autoridade patriarcal da casa-grande".

Em 1759, as reformas realizadas por Sebastião José de Carvalho e Mello, o Marquês de Pombal, primeiro-ministro de Portugal de 1750 a 1777, vão extinguir o único "sistema" de educação do Vice-Reinado do Brasil com a expulsão da Companhia de Jesus. A reforma pombalina, que se insere no contexto histórico do despotismo esclarecido e do enciclopedismo francês, com o objetivo de recuperar o atraso da metrópole lusitana em relação a outros países, prega a abertura do ensino às ci- 
ências experimentais, tornando-o mais prático e utilitário, despertando um número cada vez maior de interessados no ensino superior. De acordo com Carvalho (1980, p. 51), "os métodos e o conteúdo da educação jesuítica foram radicalmente reformulados. A ênfase deslocou-se para as ciências físicas e matemáticas. A nova faculdade de Filosofia concentrou-se nas ciências naturais - a física, a química, a zoologia, a botânica, a mineralogia [...]. O Iluminismo atingia Portugal, finalmente".

Do Brasil, entretanto, o lluminismo permanecia distante. Da expulsão até as primeiras providências para substituição dos educadores jesuítas decorreram 13 anos. Neste período, desmantelou-se parte da estrutura administrativa do ensino jesuítico: substituiu-se a uniformidade de sua ação pedagógica pela diversificação das disciplinas isoladas. $\bigcirc$ Estado tentou assumir, pela primeira vez, os encargos da educação, mas os mestres leigos das aulas e escolas régias, recém-criadas, se revelaram incapazes de assimilar toda modernidade que norteava a iniciativa pombalina.

Por conta ainda desta intervenção, registra-se a primeira mudança no que diz respeito aos custeios da educação no Brasil. Até 1759, as escolas mantidas pelos jesuítas eram financiadas pelas contribuições dos usuários e lgrejas, através de doações. A partir de então, institui-se o tributo de subsídio literário, imposto por alvará régio e com vigência até o início do século XIX. Por outro lado, a manutenção, por parte dos padres católicos, de colégios para formação de sacerdotes e de seminários para a formação do clero secular, fez com as características da educação colonial se perpetuassem. Os novos mestres-escolas e os preceptores da aristocracia rural foram formados ainda pelos Jesuítas, sendo, de certa forma, mantenedores de sua obra pedagógica: os mesmos objetivos, os mesmos métodos, a permanência do apelo à autoridade e à disciplina; o combate à originalidade, à iniciativa e à criação individual.

Somente com a chegada da família real e da corte lisboeta, em 1808, a paisagem cultural do Brasil começaria a mudar. $\bigcirc$ país passa a viver um ambiente de efusão cultural, em que se destacam a criação do Museu Real, do Jardim Botânico, da Biblioteca Pública e a Imprensa Régia. No setor educacional, surgem os primeiros cursos superiores, embora baseados em aulas avulsas e com um sentido profissional prático. Dentre eles, distinguiam-se a Academia Real da Marinha e a Academia Real Militar (depois transformada em Escola Militar de Aplicação), que formavam engenheiros civis e preparavam a carreira das armas. Já os cursos médico-cirúrgicos do Rio de Janeiro e da Bahia foram o embrião das primeiras Faculdades de Medicina. Assinala-se ainda a presença da Missão Cultural Francesa, que possibilitou a criação da Real Academia de Desenho, Pintura, Escultura e Arquitetura Civil, em 1820.

Com a vinda de D. João VI, portanto, nascia o ensino superior brasileiro e o processo de autonomia política que iria culminar na Independência do país décadas depois ${ }^{1}$. A educação do período colonial, conclui Xavier (1980, p. 22), ficou reduzida a algumas poucas escolas e aulas régi-

\footnotetext{
Para mais detalhes sobre o processo de implantação do ensino superior brasileiro, conferir o capítulo três (Ciência e educação superior no Brasil do século XIX), de Schwartzman (1979).
} 
as. "E o Brasil, saindo da fase joanina com algumas instituições de educação elitária (escolas técnicas superiores), chegou à Independência destituído de qualquer forma organizada de educação escolar". A partir do governo de D. Pedro I, inicia-se um processo de transferência de poder para um mesmo grupo de beneficiários, com acréscimo dos "letrados" aos cargos administrativos e políticos para o preenchimento do quadro funcional do Estado. As Faculdades de Direito, de São Paulo e Recife, criadas em 1827, passam a formar os futuros funcionários do governo.

Em 1834, um Ato Adicional do Imperador promove uma das primeiras políticas de descentralização administrativa, conferindo às Províncias o direito de legislar sobre a instrução pública e de promover estabelecimentos próprios, excluindo os de níveis superiores, o que vai possibilitar uma dualidade de sistemas, com a superposição de poderes (provincial e central) relativamente ao ensino primário e secundário. Ao poder central ficou reservado o direito de promover e regulamentar a educação no Rio de Janeiro e a educação de nível superior, em todo o Império. Às Províncias foi delegada a incumbência de regulamentar e promover a educação primária e média em suas próprias jurisdições (ROMANELLI, 1999).

Com o ensino secundário destinado a preparar candidatos ao ensino superior, o seu conteúdo acabou por ganhar um caráter propedêutico. Nas províncias, o sistema escolar não passou da tentativa de reunião das antigas aulas régias em liceus, de forma desorganizada. Motivo: um falho sistema tributário e a conseqüente falta de recursos. No vazio do Estado, boa parte do ensino secundário ficou a cargo da iniciativa privada (princi- palmente religiosa) e o ensino primário foi relegado ao abandono, sobrevivendo pelo sacrifício de alguns mestres-escolas, que destituídos de habilitação profissional, só encontravam emprego na educação.

Do legado do Império, além do conjunto de instituições públicas para a formação das elites, restou uma série de debates sobre a estruturação de uma educação nacional, com a tentativa da criação de um sistema em que a educação popular era considerada um requisito fundamental - sinônimo de liberdade e riqueza; antônimo de pobreza e despotismo. Mas os acalorados debates sobre a educação popular na Assembléia Constituinte e Legislativa tiveram como resultado apenas a "proclamação" de sua importância. Já o projeto de criação das universidades foi facilmente aprovado. Segundo Xavier (1980, p. 61-63), "não se questionou seriamente da necessidade ou finalidade de Universidades em um país destituído de educação elementar... [o que] veio apenas legalizar uma situação de fato - a omissão do poder central em relação à educação popular".

A estrutura geral do ensino ficou da seguinte forma: o poder central encarregouse do ensino superior em todo o País e os demais níveis ficaram a cargo das províncias - com exceção do Colégio Pedro II, nomeado em homenagem ao nosso segundo governante imperial, que deveria servir de modelo às escolas provinciais. A carência de recursos e a falta de interesse das elites regionais impediram a organização de uma rede eficiente de escolas. No balanço final, o ensino secundário foi assumido, em geral, pela iniciativa particular, especialmente pela lgreja. $\bigcirc$ ensino primário, novamente, ficou abandonado. 
Ao final do Império, o quadro geral do ensino era o seguinte: poucas escolas primárias (com 250 mil alunos para um país com cerca de 14 milhões de habitantes, dois quais $85 \%$ eram analfabetos), liceus provinciais nas capitais, colégios particulares nas principais cidades, alguns cursos normais e os cursos superiores que forjavam o projeto elitista (para formação de administradores, políticos, jornalistas e advogados), que acabou se transformando num elemento poderoso de unificação ideológica da política imperial.

Como assevera Carvalho (1980, p. 64), "no Brasil imperial, como na Turquia de Ataturk [...], a educação era a marca distintiva da elite política. Havia um verdadeiro abismo entre essa elite e o grosso da população em termos educacionais".

\section{As primeiras tentativas de ruptura durante a transição republicana}

$\mathrm{Na}$ transição republicana, com a adesão de parte da elite intelectual aos ideais do liberalismo burguês, é atribuída à educação a tarefa heróica de promover a reconstrução da sociedade. A primeira Constituição da República, de 1891, institui o sistema federativo de governo e, conseqüentemente, a descentralização do ensino. Em seu artigo 35 , itens $3^{\circ}$. e $4^{\circ}$., reservou à União o direito de criar instituições de ensino superior e secundário nos estados e prover a instrução secundária no Distrito $\mathrm{Fe}$ deral. Aos estados competia prover e legislar sobre a educação primária, além do ensino profissional (que compreendia, na época, as escolas normais de nível médio para moças e as escolas técnicas para ra- pazes). Era a consagração do sistema dual que vinha do regime anterior, ampliando a distância entre a educação da classe dominante (escolas secundárias acadêmicas e escolas superiores) e a educação do povo (escola primária e escola profissional).

O que fez a diferença a partir de então foi a emergência de novos estratos sociais, com a substituição da massa homogênea dos agregados rurais e dos pequenos artífices e comerciantes da zona urbana por uma composição social mais heterogênea, pela divergência de interesses, origens e posições. Deste panorama faziam parte uma camada média de intelectuais, os militares com alto prestígio, os primeiros passos de uma burguesia industrial e todo um contingente de imigrantes, que se ocupavam da lavoura ou das profissões liberais urbanas. Desta forma, sustenta Romanelli (1999, p. 42), "todo esse complexo organismo social já não podia comportar-se em instituições de caráter simplista".

A pressão não tardou a provocar uma ruptura. A instituição da escola, calcada no princípio da dualidade social, foi aos poucos tendo seus alicerces comprometidos pelo crescimento de complexas e diversificadas camadas sociais. Ao nível das políticas públicas, houve várias tentativas de reforma por parte do governo central. A primeira tentativa veio com Benjamin Constant, à frente da pasta ministerial da Instrução Pública, Correios e Telégrafos, o primeiro ministério dedicado, ainda que não exclusivamente, à educação ${ }^{2}$. Benjamin Constant tinha os seguintes objetivos: a substituição do currículo acadêmico por um currículo enciclopédico (com a inclusão de

\footnotetext{
${ }^{2}$ Como curiosidade histórica, vale lembrar que a última fala oficial do Imperador Pedro Il correspondeu ao pedido de criação de um ministério dos negócios da instrução e duas universidades (ALBUQUERQUE, 1993, p. 21).
} 
disciplinas científicas); o ensino seriado; maior organicidade do sistema em todos os níveis de ensino; e, por fim, a criação do Pedagogium, centro de aperfeiçoamento do magistério.

A ausência de uma estrutura institucional e de apoio político de parte da elite, que via nas idéias do ministro uma ameaça à formação da juventude, impediu sua execução. $\bigcirc$ insucesso desta reforma, entretanto, foi apenas um exemplo dos limites e das frustrações da República que acabava de nascer, quando outras reformas foram frustradas. Por mais que decepcionasse os idealistas republicanos, "a nova cara política era mais parecida com a cara real do país e era por ela que se tinha que dar início à nova jornada. Uma das fraquezas das elites vitoriosas é a sua incapacidade de reproduzir novas elites adequadas para novas tarefas. Elas são as primeiras vítimas de seu próprio êxito" (CARVALHO, 1980, p. 183).

As intervenções governamentais seguintes representaram marchas e contramarchas na evolução da estrutura educacional. A Lei Orgânica Rivadávia Corrêa, no governo do marechal Hermes da Fonseca, em 1911, suprimiu o caráter oficial do ensino, dando total autonomia e liberdade aos estabelecimentos. Logo a seguir, a reforma Carlos Maximiliano reoficializa o ensino, reforma o Colégio Pedro II e regulamenta o ingresso nas escolas superiores. Em 1925, no governo de Arthur Bernardes, ocorre a reforma Rocha Vaz, última tentativa no período de se instituir normas regulamentares para o ensino, cujo mérito foi buscar estabelecer, pela primeira vez, um acordo entre a União e os estados para a promoção da educação primária e para a eliminação dos exames preparatórios e parcelados.
Todas essas reformas, além de frustradas, representaram posições isoladas dos comandos políticos; não foram, em nenhuma hipótese, orientadas por uma política nacional de educação e acabaram por perpetuar o modelo educacional herdado do período colonial. Com isto, podemos afirmar que durante os primeiros anos da República a importação da ideologia liberal atuou de forma difusa: ao mesmo tempo em que validou um arranjo político em favor de uma parte da elite, produziu um imediato ressurgimento das propostas para a adequação da estrutura educacional aos desígnios de uma nova ordem "democrática" em implantação.

Somente a demanda para a ampliação da oferta de ensino de elite (o médio e o superior) às classes médias em ascensão foi atendida pela União, difundindo-se a ideologia da ascensão social pela escolarização. Mais do que por exigências econômicas e sociais, a mobilização em torno destas propostas se deu pela instabilidade política num período de rearticulação das elites. $\bigcirc$ atendimento desta demanda funcionou como canalização das insatisfações sociais, o que explica o sucesso e a incorporação dos pressupostos educacionais liberais em todas as camadas sociais. A expansão das oportunidades e a reforma das instituições escolares representavam um custo menor às elites do que a alteração da distribuição de renda e das relações de poder e, além disso, acalmava as frações mais combativas das camadas médias.

Enquanto isso, em nível internacional, despontava uma nova dimensão do ideário liberal, que se desdobrava para além do individualismo original e ganhava um papel de reconstrutor social. No plano educa- 
cional, essa tendência irá se expressar na pedagogia pragmática da Escola Nova, baseada no pensamento do norte-americano John Dewey, que propunha um modelo escolar de cunho reformista, necessário a uma sociedade com tendências a produzir privilégios e desigualdades, mas que subsiste pela expectativa de mudança e ascensão social. Pelo vislumbre da democracia e do progresso, atendendo às aspirações das classes médias e, em parte, ao conservadorismo da classe dominante, o pensamento escola-novista foi assimilado por vários educadores brasileiros, com divergências apenas no que diz respeito à orientação geral (revolucionária-reformista ou conservadoramente democrática), mantendo um horizonte comum na interpretação das funções da escola, consolidando-se em uma ideologia educacional que influenciará o desenvolvimento do ensino brasileiro.

primeiro documento de expressão desta ideologia é o Manifesto dos Pioneiros da Educação Nova, de 1932, que buscava superar as tentativas parciais de reforma até então efetuadas e imprimir uma direção única, clara e definida do movimento de renovação da educação nacional. Para tanto, baseado no direito individual à educação, determinava que o Estado, representante da coletividade, assumisse a responsabilidade da organização do ensino, com a tarefa de tornar a escola acessível, em todos os seus graus, aos cidadãos mantidos em condições de inferioridade econômica. Os pioneiros advertem, porém, que este acesso não deveria obedecer a um arrolamento obrigatório (da escola infantil à universidade), mas apenas à abertura da escola oficial para todas as crianças, de 7 a 15 anos, com a exceção das já confiadas às escolas privadas.

Esta "tangente burguesa" defensora da escola pública, como gostava de nomear o cientista social Florestan Fernandes ${ }^{3}$, tinha como referência dois significados básicos e contraditórios da democracia moderna: a definição de democracia em sentido descritivo, como forma de governo e modo de vida de uma sociedade de mercado e capitalista; e a definição de democracia em sentido normativo, como forma de governo e modo de vida de uma sociedade interessada em garantir, para todos os seus membros, a liberdade necessária à concretização e ao desenvolvimento de suas capacidades (GARCIA, 2002). Esta corrente tinha como ideal um sistema de ensino em que educação popular de massas e formação especializada apareciam como complementares, sendo, portanto, um mecanismo eficiente e não autocrático de recrutamento dos mais capazes indivíduos de todos as camadas sociais.

A perspectiva dos pioneiros, portanto, corrobora uma noção democrática de elite, àquela baseada na educação. Nesta concepção, à medida que a educação for estendendo a sua influência, despertadora de vocações, vai penetrando até as camadas mais obscuras, para aí, entre os pró-

\footnotetext{
${ }^{3}$ Segundo Florestan (FERNANDES, 1995, p. 194-195) apesar das contradições que atravessavam o movimento dos pioneiros, os esforços dessa "tangente burguesa" na área educacional devem ser elogiados por buscar colocar o Brasil num novo patamar. Era uma utopia "reformista" de superação de etapas, mas uma utopia que visava oferecer a todas as classes sociais um mínimo de dignidade. No entanto, estas "inteligências radicais", seguidores da obra abolicionista, não lograram atingir os objetivos visados. "Por quê? Porque no Brasil, para as elites das classes dominantes, o que era importante, o que era funcional, era deseducar, não educar; educar os filhos das elites e deseducar a massa; manter a massa fora da escola ou então colocar a massa dentro da escola como futura mão-de-obra, qualificada ou semiqualificada, de vários graus de desenvolvimento econômico."
} 
prios operários, descobrir "o grande homem, o cidadão útil", que o Estado tem o dever de atrair submetendo a uma prova constante as idéias e os homens, para os elevar e selecionar, segundo o seu valor ou a sua incapacidade (GARCIA, 2002). Sobrevivia, desta forma, uma concepção elitista com a renovada defesa da necessária formação de "líderes condutores", a mesma prioridade dos jesuítas no início do processo de desenvolvimento da estrutura educacional brasileira.

Assim, fora a Igreja Católica, que se opunha ao ensino laico e ao monopólio estatal (em descarte no próprio Manifesto), nem mesmo a fase mais autoritária do período varguista, durante o Estado Novo que se inicia em 1937, deixou de incorporar o ideário e a retórica escola-novista. As primeiras impressões da lgreja sobre a Revolução de 1930 foram de precaução e assombro: significava a vitória do Movimento Tenentista, cerne de "perigosas" idéias, baseadas na associação do liberalismo com o positivismo, propositora da substituição da moral religiosa pela crença nos poderes da técnica e da ciência como critérios para organização da vida e da ação social. É deste movimento que saíra, por exemplo, o maior mito do socialismo brasileiro, o comunista Luís Carlos Prestes.

Na esfera educacional, a subida de Getúlio Vargas ao poder, na visão da lgreja, representava o fortalecimento dos ideais escola-novistas, que com a defesa do ensino laico e da escola pública colocavam em risco o predomínio das escolas confessionais. Nas palavras de Alceu Amoroso Lima, militante católico, o movimento revolucionário poderia ser definido pela "obra da Constituição sem Deus, da esco- la sem Deus, da família sem Deus" (SCHWARTZMAN; BOMENY; COSTA, 1984, p. 55).

Mas logo se consolidava o novo regime e a lgreja não tardaria em encontrar o seu espaço. A referência para a ação vinha do movimento mineiro de renovação católica, que já na década de 20 estabeleceu fortes laços com os grupos sociais em ascensão, sem deixar de corroborar antigas ligações com o poder político conservador. $\bigcirc$ próprio Alceu Amoroso Lima, expoente deste movimento, reconhecendo uma "corrente racional, tradicional e cristã" entre os revolucionários de 1930, clama aos católicos à luta pela incorporação de suas reivindicações no futuro estatuto político do país.

pacto toma forma numa carta do ministro Francisco Campos a Getúlio Vargas. Na missiva de 18 de abril de 1931, o ministro defende as propostas de introdução do ensino religioso facultativo nas escolas públicas e o reconhecimento constitucional do catolicismo como a religião da maioria dos brasileiros. No mesmo mês, depois de 40 anos, o ensino religioso volta a ser permitido nas escolas públicas, dando provas de que o processo o Estado laico brasileiro era uma falácia. Mais do que um sinal de confirmação do pacto, o decreto criou a expectativa no movimento católico de que o Estado pudesse ouvir as reivindicações da lgreja contra o "processo de laicização da vida social". Entretanto, sinais posteriores vão demonstrar que a incorporação da lgreja ao projeto político de Francisco Campos tinha um caráter meramente instrumental, não correspondendo necessariamente a uma convicção ética e religiosa mais profunda. 
Ainda assim, a neutralização dos reformadores escola-novistas, mais por razões políticas do que ideológicas, não impediu a reedificação do discurso liberal com uma nova roupagem. De acordo com Xavier (1990, p. 82), "as reformas educacionais empreendidas nas décadas de 30 e 40 visavam, a um só tempo, a responder às exigências político-ideológicas do momento e às pressões sociais traduzidas e reforçadas pelo novo ideário". Desta forma, embora não concretizassem plenamente o "plano de reconstrução nacional" proposto pelos pioneiros da Escola-Nova, justificavam-se dentro do seu espírito geral as ambigüidades presentes no Manifesto, atendendo ao novo que podia brotar, mas preservando a tradicional estrutura dualista, elitista e acadêmica do ensino brasileiro - pelo menos, afirma Xavier (1980), é o que se pode concluir das exposições de motivos dos ministros Francisco Campos e Gustavo Capanema e das leis que organizaram o sistema público brasileiro nas décadas de 1930 e 1940.

\section{Conclusão}

Nos quatro séculos de predomínio da economia agroexportadora, a educação brasileira voltou-se exclusivamente à formação das camadas superiores, no intuito de prepará-las para as atividades político-burocráticas e das profissões liberais, a partir de um ensino humanístico e elitista - quase sempre a cargo ou sob a influência da "iniciativa privada" religiosa. Da mesma forma como faltou, em Portugal e no Brasil, um movimento social mais profundo que buscasse a criação de um ethos científico, do qual o sistema universitário europeu seria o grande modelo, segundo a interpretação de Schwartzman (1979, p. 52), o mesmo ocorreu para constituição de um sistema de educação pública no Brasil, de caráter laico e universal.

No entanto, a gradual substituição de um modelo econômico exclusivamente agrário-exportador por um parcialmente urbano-industrial, em concomitância ao colapso do liberalismo ocidental e ao fortalecimento das variadas manifestações de totalitarismo, acarretará na cisão oligárquica da República Velha e no advento na Revolução de 1930. O incremento da industrialização, a crescente urbanização e a introdução de um contingente cada vez maior de estratos médios e populares vão resultar na transformação da demanda social pela educação, que organizada em distintos movimentos políticos, reclama a organização de um sistema nacional de ensino.

A partir de então, a escolarização da população brasileira, relegada a um plano secundário pelo poder político, passa a ter destaque na dinâmica dos conflitos sociais, influenciando, cada vez mais, o discurso e a ação do Estado. A posterior e progressiva organização da estrutura educacional brasileira terá três momentos marcantes: o de expansão da demanda social, durante a Primeira República, cuja melhor expressão será o movimento escola-novista; o de consolidação, através das reformas Francisco Campos (1931-1932) e Gustavo Capanema (1942-1946); e o terceiro momento, de crítica e balanço, no pós-1946, que culmina com a promulgação da primeira Lei de Diretrizes e Bases da Educação Nacional, em 1961, pelo governo João Goulart. 
No entanto, em todos estes momentos históricos irá predominar a assistência ao ensino das elites e o despropósito com a universalização da educação popular, condição necessária para a consolidação da democracia brasileira. Somente na década de 1990, durante os dois governos do expresidente Fernando Henrique Cardoso, é que o desenvolvimento do ensino fundamental será estimulado a ampliar de forma efetiva as oportunidades de acesso, ainda que em termos qualitativos ${ }^{4}$ continue a demandar esforços significativos - sem contar os desafios que significam o baixo atendimento na educação infantil e a difícil questão do ensino médio, principalmente o da rede pú- blica, que não consegue preparar seus alunos para o ingresso universitário.

A esperança é que a partir de uma nova conjuntura política essa importante dívida social seja resgatada para que o Brasil finalmente possa ingressar no rol das nações que oferecem a sua população o maior legado da civilização ocidental: o direito a uma educação que sirva não só para a reprodução material e o desenvolvimento econômico, como também para a elevação sociocultural que permita a construção de uma identidade nacional soberana e solidária - a base de uma sociedade mais justa e democrática.

Recebido em: 25/04/2003

Aceito para publicação: 17/12/2003

\footnotetext{
${ }^{4}$ A baixa qualidade do ensino público brasileiro pode ser medida pelos altos índices de evasão e repetência, assim como pelas avaliações internacionais que colocam os nossos alunos em patamares baixíssimos. Como causa principal, evidencia-se a formação precária do corpo docente, que sofre com a desvalorização social da profissão e com a falta de estrutura e apoio na maioria das instituições de ensino (INSTITUTO NACIONAL DE ESTUDOS E PESQUISAS EDUCACIONAIS, 2003).
} 


\section{ABSTRACT}

\section{The origins of Education in Brazil: from the catholic hegemony until the first attempts of teaching organization}

This article analyzes the effects of the process of European modernization in Brazil, especially in what refers to the delay of the introduction of a teaching structure organized based on in a national system. In agreement with our hypothesis, in the same way as it lacked in Brazil a social movement that it looked for the creation of a scientific ethos, of which the European university system would be the great model, according to Simon Schwartzman's interpretation, the same happened for the constitution of a system of public education, of character secular and universal.

Key-words: Education. History. Catholic Church. Higher education. Basic Education. Republic.

\section{RESUMEN}

\section{Los origenes de la educación en Brasil da hegemonia católica a las primeiras tentativas de organización de la enseñanza.}

Este artículo analiza los efectos del proceso europeo de modernización en Brasil, sobre todo en lo que se refiere al retraso de la introducción de una estructura de instrucción organizada con base en un sistema nacional. De acuerdo con nuestra hipótesis, de la misma manera como faltó en Brasil un movimiento social que buscara la creación de genios científicos del cual el sistema universitario europeo sería el gran modelo, según la interpretación de Simon Schwartzman, el mismo pasó para la constitución de un sistema de educación pública, de carácter seglar y universal.

Palabras-clave: Educación. Historia. Iglesia Apostólica Romana. Educación Superior. Educación Básica. República. 


\section{Referências bibliográficas}

ALBUQUERQUE, R. C. Educação e modernidade no Brasil. In: FÓRUM NACIONAL AS BASES DO DESENVOlVIMENTO MODERNO, 5., 1993, São Paulo. Anais... São Paulo: Nobel, 1993.

ARAUJO, M. C. S. O Estado Novo. Rio de Janeiro: Zahar, 2000. (Descobrindo o Brasil). CARVALHO, J. M. A construção da ordem: a elite política imperial. Rio de Janeiro: Campus, 1980.

CASTRO, M. H. G. O sistema educacional brasileiro: tendências e perspectivas. In: VELLOSO, J. P. R.;

ALBUQUERQUE, R. C. (Coord.). Um modelo para a educação do século XXI. Rio de Janeiro: José Olympio, 1999.

CUNHA, L. A. Educação, estado e democracia no Brasil. 3. ed. São Paulo: Cortez; Niterói, RJ: EDUFF; Brasília: Flacso do Brasil, 1999.

FERNANDES, F. A contestação necessária: retratos intelectuais de inconformistas e revolucionários. São Paulo, Ática, 1995.

GARCIA, S. G. Destino ímpar: sobre a formação de Florestan Fernandes. São Paulo: Ed. 34, 2002.

INSTITUTO NACIONAL DE ESTUDOS E PESQUISAS EDUCACIONAIS. Estudo do Inep mostra que $41 \%$ dos estudantes não terminam o ensino fundamental. Outras Notícias . Brasília, DF, 11 mar. 2003. Disponível em: http://www.inep.gov.br/imprensa/noticias/ outras/news03 6.htm.. >. Acesso em: $30 \mathrm{dez}$. 2004.

OLIVEIRA, M. M. O desenvolvimento da ação sindical do ensino privado brasileiro. Rio de Janeiro: PREAL Brasil, CPDOC/ FGV, fev. 2001. (Preal Debates; n. 7).

Os empresários da educação e o sindicalismo patronal: o Sindicato dos Estabelecimentos Privados

de Ensino no Estado do Rio de Janeiro. Bragança Paulista, SP: Ed. Universidade São Francisco, 2002a.

- Os empresários de educação básica e a nova divisão de trabalho da educação nacional. In: NEVES, L. (Org.). O empresariamento da educação: novos contornos do ensino superior no Brasil dos anos 1990. São

Paulo: Xamã, 2002c. 
. A política governamental de ciência e tecnologia: da C\&T à CT\&I. In: NEVES, L. (Org.). O empresariamento da educação: novos contornos do ensino superior no Brasil dos anos 1990. São Paulo: Xamã, 2002b.

PETITAT, A. Produção da escola: produção da sociedade. Porto Alegre: Artes Médicas, 1994.

PARSONS, T. The system of modern societies. Nova Jersey: Englewood Cliffs, 1971.

ROMANELLI, O. História da educação no Brasil. 22. ed. Petrópolis: Vozes, 1999.

SALEM, T. Do Centro Dom Vital à Universidade Católica. In: SCHWARTZMAN, S. (Org.) Universidades e instituições científicas no Rio de Janeiro. Brasília, DF: CNPq, 1982.

SCHWARTZMAN, S. Ciência, universidade e ideologia: a política do conhecimento. Rio de Janeiro: Zahar, 1981.

. Formação da comunidade científica no Brasil. São Paulo: Ed. Nacional; Rio de Janeiro: Finep, 1979.

SCHWARTZMAN, S.; BOMENY, H. M. B.; COSTA, V. M. R. Tempos de Capanema. Rio de Janeiro, Paz e Terra; São Paulo, Edusp, 1984.

SOUZA, R. F. Templos de civilização: a implantação da escola primária graduada no Estado de São Paulo (1890-1910). São Paulo: UNESP, 1988.

XAVIER, M. E. S. P. Poder político e educação de elite. São Paulo: Cortez, 1980.

\section{Correspondência}

contatosineperi@urb.br 